\title{
Hydrologic Responses to Land Use Change in the Loess Plateau: Case Study in the Upper Fenhe River Watershed
}

\author{
Zhixiang Lu, ${ }^{1,2}$ Songbing Zou, ${ }^{1}$ Zuodong Qin, ${ }^{3}$ Yonggang Yang, \\ Honglang Xiao, ${ }^{1}$ Yongping Wei, ${ }^{4}$ Kai Zhang, ${ }^{5}$ and Jiali Xie ${ }^{6}$ \\ ${ }^{1}$ Key Laboratory of Ecohydrology of Inland River Basin, Cold and Arid Regions Environmental and Engineering Research Institute, \\ Chinese Academy of Science, Lanzhou 730000, China \\ ${ }^{2}$ University of the Chinese Academy of Science, Beijing 100049, China \\ ${ }^{3}$ Institute of Loess Plateau, Shanxi University, Taiyuan 030006, China \\ ${ }^{4}$ The Australia China Centre on Water Resources Research, University of Melbourne, Parkville, VIC 3010, Australia \\ ${ }^{5}$ School of Soil and Water Conservation, Beijing Forestry University, Beijing 100083, China \\ ${ }^{6}$ Key Laboratory of Desert and Desertification, Cold and Arid Regions Environmental and Engineering Research Institute, \\ Chinese Academy of Science, Lanzhou 730000, China
}

Correspondence should be addressed to Songbing Zou; zousongbing@lzb.ac.cn

Received 20 November 2014; Revised 12 March 2015; Accepted 16 March 2015

Academic Editor: Yongqiang Zhang

Copyright (c) 2015 Zhixiang Lu et al. This is an open access article distributed under the Creative Commons Attribution License, which permits unrestricted use, distribution, and reproduction in any medium, provided the original work is properly cited.

\begin{abstract}
We applied an integrated approach to investigate the impacts of land use and land cover (LULC) changes on hydrology at different scales in the Loess Plateau of China. Hydrological modeling was conducted for the LULC maps from remote sensing images at two times in the Upper Fenhe River watershed using the SWAT model. The main LULC changes in this watershed from 1995 to 2010 were the transformation of farmland into forests, grassland, and built-up land. The simulation results showed that forested land contributed more than any other LULC class to water yield, but built-up land had most impact due to small initial loss and infiltration. At basin scale, a comparison of the simulated hydrological components of two LULC maps showed that there were slight increases in average annual potential evapotranspiration, actual evapotranspiration, and water yield, but soil water decreased, between the two intervals. In subbasins, obvious LULC changes did not have clear impacts on hydrology, and the impacts may be affected by precipitation conditions. By linking a hydrological model to remote sensing image analysis, our approach of quantifying the impacts of LULC changes on hydrology at different scales provide quantitative information for stakeholders in making decisions for land and water resource management.
\end{abstract}

\section{Introduction}

Changing land use represents the greatest human impact on the surface of the earth, and between one-third and onehalf has been altered over the last 300 years [1-3]. Land use directly impacts the hydrologic components of a watershed, such as evapotranspiration, surface runoff, groundwater recharge, and streamflow [4-7]. Many previous studies from around the world have demonstrated that land use significantly impacts hydrological processes [8-15]. For example, Ghaffari et al. (2010) found that a $34.5 \%$ decrease of grassland with increases of shrubland (13.9\%) and rain-fed agriculture
(12.1\%) led to a $33 \%$ increase in the amount of surface runoff and a $22 \%$ decrease in the groundwater recharge in northwest Iran [8]. Nie et al. (2011) revealed the effects of urbanization and agricultural development on the runoff in North America [9], and Wang et al. (2014), Li et al. (2015), and Yao et al. (2015) revealed the effects of urbanization, land use patterns, and changes on the runoff, temperature, evapotranspiration, and surface climate in Chinese landscapes [10-12]. LópezVicente et al. (2013) and Ohana-Levi et al. (2015) modeled the effects of land use change on the runoff and sediment yield in Europe's Pyrenees and rainfall-runoff relationships in an Eastern Mediterranean watershed, respectively [13, 14]. 
Wang et al. (2014) assessed the impacts of land use changes on evapotranspiration, quickflow, infiltration, and baseflow in the upstream regions of the Three Gorges reservoir in China [15]. Assessing impacts of land use and land cover (LULC) changes on hydrology is essential for watershed management and ecological restoration $[7,15,16]$.

In general, regional impacts of land use change on hydrology vary from place to place and need to be considered for specific circumstances and environments $[15,16]$. The Loess Plateau of western China is infamous for serious soil erosion and is the main source of sediment in the middle reaches of the Yellow River and has become the focus of world attention. As early as the 1950s, China started soil and water conservation works on the Loess Plateau in order to improve the local environment and mitigate sediment accessions to the middle reaches of the Yellow River, and works were expanded after the 1970s $[17,18]$. As a consequence, land use in the Loess Plateau has undergone great changes. Likewise, in the past century, a range of management measures were carried out in the Fenhe River Basin on the eastern margin of the Loess Plateau. Some research has been done on the impacts of land use change on basin hydrology [1922], but research on the contribution of individual LULC to the total runoff and the impacts of LULC changes on watershed hydrology is lacking. In particular, there is a lack of information for evaluating the benefits of soil and water conservation in the Fenhe River basin and the whole of the Loess Plateau, where it is difficult to distinguish the impacts of LULC changes on hydrology. Greater understanding of the contribution of individual LULC change to runoff and the impacts of LULC changes on the hydrology at different scales is needed to guide comprehensive natural resources management in this region.

Methods for assessing hydrological impacts of land use changes in watersheds include comparisons of paired catchments, statistical analysis, and hydrological modeling [5, 23, 24]. Among these approaches, hydrological modeling is the most suitable one for use in scenario studies at different scales. Widely used hydrological models in studies on the impacts on watershed hydrology include the Hydrologic Simulation Program, FORTRAN, the Soil and Water Assessment Tool (SWAT), and WaTEM/SEDEM [4, $5,9,15]$. The SWAT model is widely used to assess hydrology and water quality in agricultural catchments around the world (https://www.card.iastate.edu/swat_articles/). It is readily available and user-friendly for data input [25].

The overall objectives of this study are to investigate the contributions of individual LULC change to runoff and to determine the impacts of LULC changes on the hydrology of the Upper Fenhe River watershed by an integrated approach that combines hydrological modeling and remotely sensed digital maps of LULC changes. To avoid the impacts of largescale water resource development projects on hydrological processes, particularly the water diversion project from the Yellow River to Fenhe River at Wanjiazhai in the study area after 2002, the period from 1990 to 2000 was selected as the study period, during which sufficient data are available. The specific objectives are (1) to investigate the LULC changes of the watershed from 1995 to 2010 with LULC maps determined by remote sensing images in 1995 and 2010; (2) to calibrate and validate the SWAT model in terms of monthly streamflow based on the DEM, soil map, land use in 1995, and climate data from 1990 to 2000; (3) to assess the hydrological effects of individual land uses, and (4) to simulate responses of hydrologic components to land use changes at basin and subbasin scales under the same climatic conditions. The results should assist decision-makers in target water resources planning and vegetation restoration on the Loess Plateau.

\section{Study Area}

The Fenhe River is located in the eastern part of the Loess Plateau, North China, and runs north to south through almost all of Shanxi Province [26]. The study area is the Upper Fenhe River watershed above the Hecha hydrological control station, which measures the amount of water and sediment entering Fenhe reservoir (Figure 1). The Upper Fenhe River watershed has an area of about $3242 \mathrm{~km}^{2}$ and lies between latitudes $38^{\circ} 00^{\prime}$ and $39^{\circ} 00^{\prime}$ and longitudes $111^{\circ} 40^{\prime}$ and $112^{\circ} 40^{\prime}$. Elevations in the basin range from 1,124 to $2,762 \mathrm{~m}$ and it has an arid to semiarid climate with a mean annual precipitation of $430 \mathrm{~mm}$. The precipitation is concentrated between the months of June and September and accounts for approximately $70 \%$ of total annual precipitation, coming in the form of high-intensity storms that often cause extreme soil erosion. The average annual temperature is $9.0^{\circ} \mathrm{C}$, with a minimum average temperature of $-5^{\circ} \mathrm{C}$ in winter and a maximum average temperature of $20^{\circ} \mathrm{C}$ in summer. The land use classes of the watershed include farmland, forest, grassland, water or wetland, built-up land, and unused land; their percentages in 2010 were $30 \%, 28.3 \%, 39.57 \%, 1.39 \%$, $0.73 \%$, and $0.01 \%$, respectively. The region is covered with highly erodible loess-derived soils. Major soil series include loess soil, cinnamon soil, brown soil, and calcium skeletal soil.

\section{Methodology}

A conceptual framework consisting of three stages was developed (Figure 2): (1) transition matrix analysis to describe the transformations of land use from 1995 to 2010; (2) hydrological modeling to simulate hydrological components for two LULC maps under the same climatic conditions; and (3) comparison of the contribution of each land use class to the watershed's water yield and their hydrological effects on subbasins.

3.1. Transition Matrix. The transition matrix of land use change was calculated as

$$
B_{i j}=\left[\begin{array}{cccc}
B_{11} & B_{12} & \cdots & B_{1 n} \\
B_{21} & B_{22} & \cdots & B_{2 n} \\
\vdots & \vdots & \cdots & \vdots \\
B_{n 1} & B_{n 2} & \cdots & B_{n n}
\end{array}\right],
$$

where $B$ is the area of a certain kind of land use, $n$ is the number of land use types in the study area, $i$ and $j(i, j=$ $1,2, \ldots, n)$ are the types of the land use before and after 


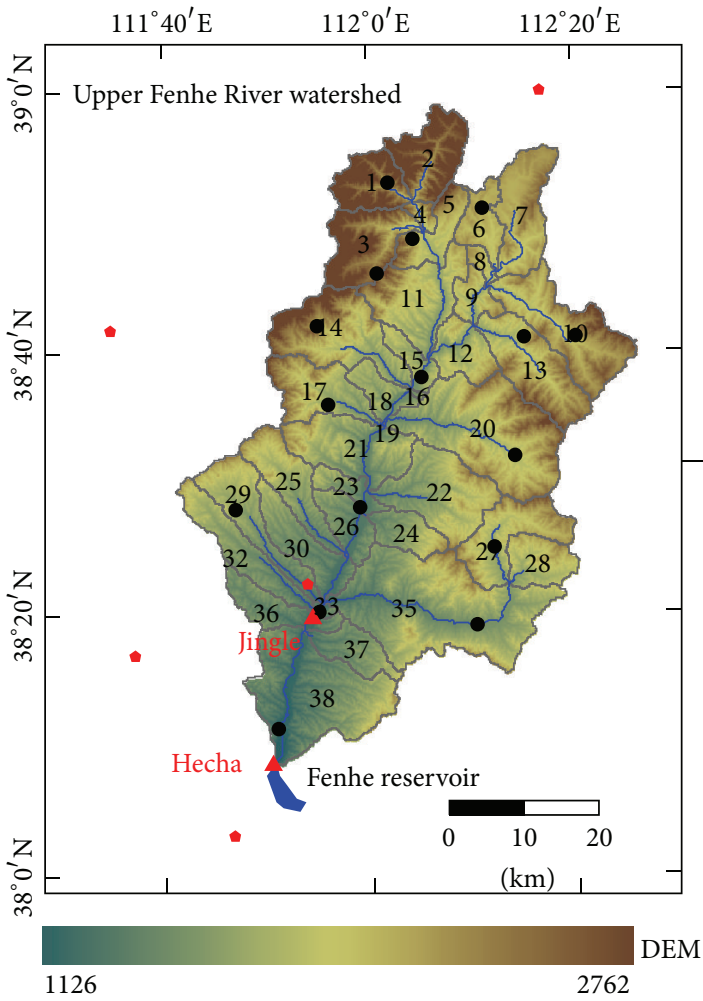

(m)

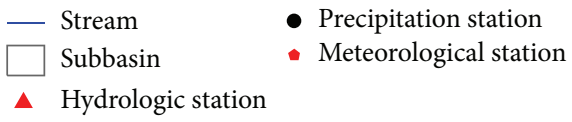

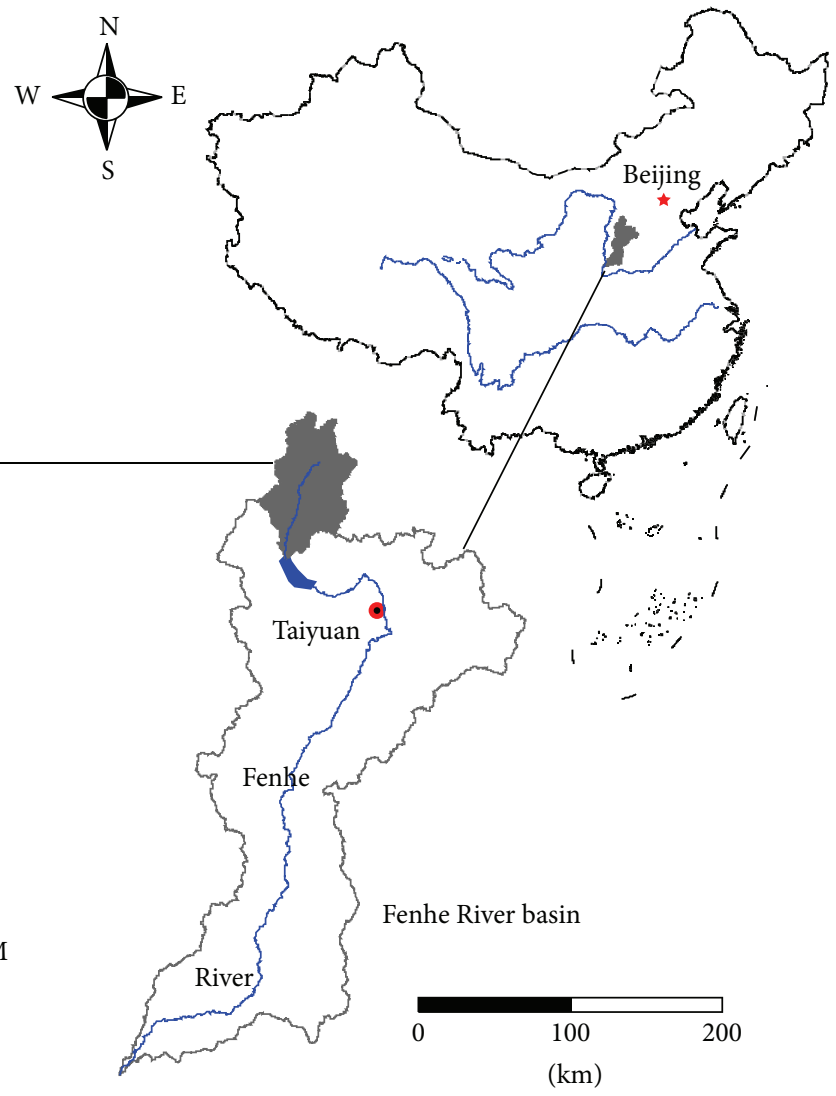

FIGURE 1: Locations of study area, hydrologic stations, and meteorological stations.

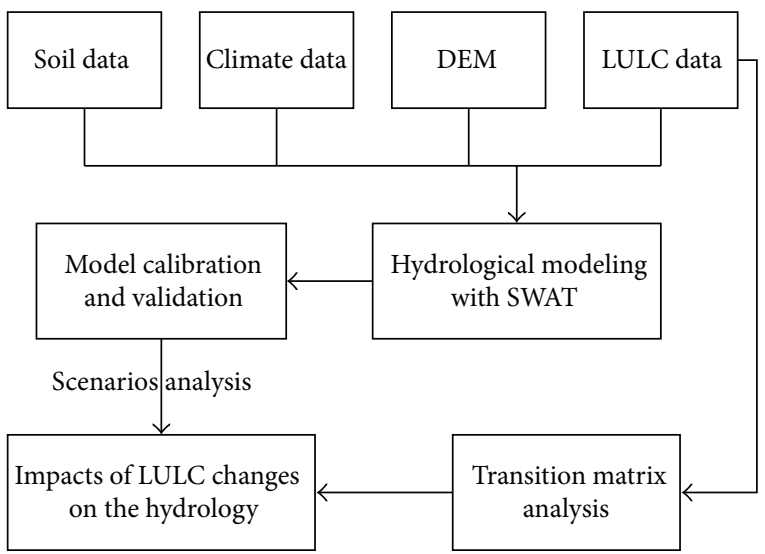

FIGURE 2: The conceptual framework for analyzing the impacts of LULC changes on the hydrology.

transition, respectively, and $B_{i j}$ is area of the land use $i$ turned into the land use $j$. The study period was defined as 1995 to 2010 because soil and water conservation practices were first implemented from 1988 to 1997, and a second tenyear conservation project was carried out from 1998 to 2007 [19, 20, 27]. The LULC maps in 1995 and 2010 represent the surface cover conditions in the latter part of the first conservation project and after the projects, respectively. The LULC map for 1995 was used as input data to calibrate the model.

\subsection{Hydrological Modeling}

3.2.1. SWAT Model Description. The SWAT 2005 model [28] was applied to data of the Upper Fenhe River watershed to assess the impacts of LULC changes on hydrological components. The SWAT model is a continuous, long-term, physically based distributed model developed to assess impacts of climate and land management on hydrological components, sediment loading, and pollution transport in watersheds [25]. In the SWAT model, a watershed is divided into subbasins. Subbasins are further divided into a series of uniform hydrological response units (HRUs) based on slope, soil, and LULC changes. Hydrological components, sediment yield, and nutrient cycles are simulated for each HRU and then aggregated for the subbasins.

Hydrological components simulated by the SWAT model include evapotranspiration (ET), surface runoff, percolation, lateral flow, groundwater flow (return flow), and transmission losses [25]. Evaporation and transpiration are simulated using exponential functions of soil depth and water content and a linear function of potential evapotranspiration (PET) and 
TABLE 1: Hydrometeorological stations in the study area.

\begin{tabular}{lccc}
\hline Types of stations & Name & Factors & Data series \\
\hline Hydrological stations & Jingle, Hecha & Monthly streamflow & 1990-2000 \\
\hline Precipitation stations & $\begin{array}{c}\text { Baergou, Haizibei, Dongzhai, Qianmalong, Gedongzi, } \\
\text { Huaidao, Dongmafang, Ninghuabao, Xinbao, Tanger, } \\
\text { Duanjiazhai, Ximafang, Suopo, Jingle, Kangjiahui, and } \\
\text { Hecha }\end{array}$ & Daily precipitation & 1990-2000 \\
\hline Meteorological stations & Ningwu, Kelan, and Jingle & $\begin{array}{c}\text { Daily precipitation and } \\
\text { maximum and minimum air } \\
\text { temperature }\end{array}$ \\
\hline
\end{tabular}

leaf area index. Hargreaves method was used to estimate PET, which was originally derived from eight years of cool-season Alta fescue grass lysimeter data from Davis, California [29], and its reference crop is similar to grassland which is the dominant land use type in this watershed. The surface runoff is estimated using a modification of the SCS curve number method with daily rainfall amounts. Percolation is calculated using the combination of a storage routing technique and a crack flow model. The lateral flow is estimated simultaneously with percolation using a kinematic storage model. The groundwater flow (baseflow) into the channel is calculated from hydraulic conductivity of the shallow aquifer, distance from subbasin to main channel, and water table height.

3.2.2. SWAT Model Inputs and Outputs. The input data used in the SWAT model included a digital elevation model (DEM), soil data, digital LULC maps, and climate data. The DEM was derived from the USGS National Elevation Dataset with a resolution of about $90 \mathrm{~m}$, and the soil data were obtained from the Resources and Environment Science Data Center, Chinese Academy of Sciences, with the scale of $1: 1,000,000$. The LULC data for two times (1995 and 2010) were used to assess the impacts of LULC change on hydrology and were derived from Landsat TM images with a spatial resolution of $30 \mathrm{~m}$ using an interpretation method. The climate data, including daily values of precipitation and minimum-maximum temperature from January 1st, 1990, to December 31, 2000, were derived from 3 meteorological stations and 16 precipitation stations located in and around the Upper Fenhe River watershed (Table 1).

The outputs of the SWAT model used in this study were hydrological components, including precipitation (P), PET, actual evapotranspiration (AET), water yield (WY), and soil water (SW).

3.2.3. SWAT Model Calibration and Validation. Simulations using the 1995 LULC map were used to calibrate monthly streamflows from January 1992 to December 1995 at two hydrological stations (Jingle and Hecha, Figure 1). After model calibration, simulations with the same model parameters and LULC map data were used to validate monthly streamflow from January 1996 to December 2000 (Table 2).

3.2.4. Performance Evaluation Criteria. The model was calibrated manually and three criteria were used to evaluate
TABLE 2: The warm-up, calibration, and validation period for the model.

\begin{tabular}{lccc}
\hline Periods & $\begin{array}{c}\text { Warm-up } \\
\text { period }\end{array}$ & $\begin{array}{c}\text { Calibration } \\
\text { period }\end{array}$ & $\begin{array}{c}\text { Validation } \\
\text { period }\end{array}$ \\
\hline Time series & $1990-1991$ & $1992-1995$ & $1996-2000$ \\
\hline
\end{tabular}

performance of model calibration and validation. The Nash-Sutcliffe efficiency (NSE) is a normalized statistic that determines the relative magnitude of the residual variance compared to the measured data variance. NSE indicates how well the plot of observed versus simulated data fits the $1: 1$ line. Coefficient of determination $\left(R^{2}\right)$ describes the degree of colinearity between simulated and measured data and the proportion of the variance in the measured data explained by the model. Percent bias (PBIAS) measures the average tendency of the simulated data to be larger or smaller than their observed counterparts [29]. The calibration and validation performance for the SWAT model were considered acceptable when $R^{2}$ and NSE were greater than 0.5 . The SWAT model performance is satisfactory when NSE is larger than 0.5 , adequate when NSE ranges from 0.54 to 0.65 , and very good when NSE is larger than 0.65 . The SWAT model is rated as satisfactory, when the absolute value of PBIAS ranges from 15 to 25 , rated good when from 10 to 15 , and very good when smaller than 10 [30].

3.3. Analyzing Hydrological Effects of Land Use Classes. The calibrated and validated hydrological model was run for each of the LULC maps (1995 and 2010) with constant DEM and soil data, from January 1990 to December 2000 (11 years), to quantify contributions of individual LULC classes to the total discharge and to evaluate impacts of LULC changes on hydrology at the basin and subbasin scales.

\section{Results and Discussion}

4.1. LULC Changes. The LULC maps of the Upper Fenhe River watershed in 1995 and 2010 are shown in Figure 3. Grassland, farmland, and forest were the main land use classes in the Upper Fenhe River watershed.

The results of the transition matrix of LULC changes between 1995 and 2010 are shown in Table 3. The transformations among farmland, forest, and grassland were the main 

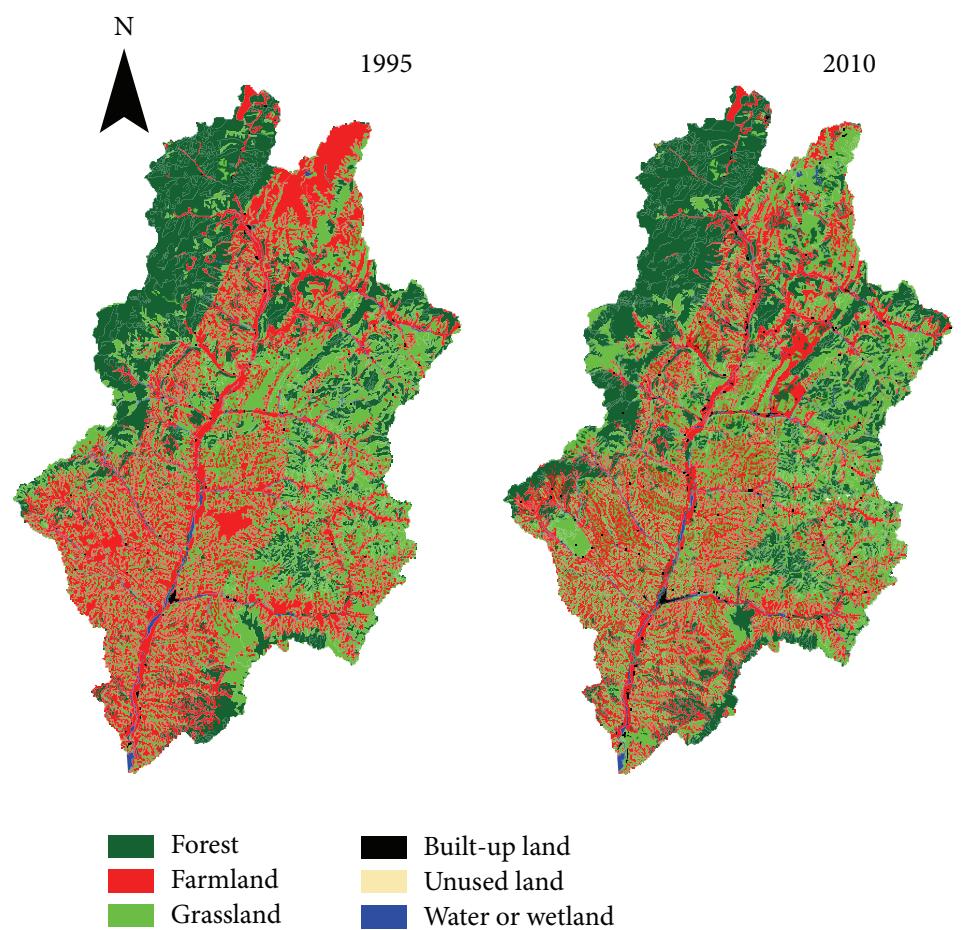

Figure 3: Maps for land uses and land cover in 1995 and 2010 in the Upper Fenhe River watershed.

TABLE 3: Transition matrix of land uses from 1995 to $2010\left(\mathrm{~km}^{2}\right)$.

\begin{tabular}{|c|c|c|c|c|c|c|c|c|}
\hline & \multirow[b]{2}{*}{ Types } & \multicolumn{7}{|c|}{2010} \\
\hline & & Farmland & Forest & Grassland & Water or Wetland & Built-up land & Unused land & Total \\
\hline \multirow{7}{*}{1995} & Farmland & 908.26 & 17.74 & 79.66 & 1.13 & 6.99 & 0.29 & 1014.07 \\
\hline & Forest & 9.68 & 840.49 & 45.88 & 0.48 & 0.82 & 0.02 & 897.37 \\
\hline & Grassland & 54.04 & 59.11 & 1157.32 & 0.09 & 2.07 & 0.08 & 1272.71 \\
\hline & Water or wetland & 0.95 & 0.06 & 0.11 & 43.32 & 0.24 & 0.00 & 44.68 \\
\hline & Built-up land & 0.03 & 0.04 & 0.01 & 0.00 & 13.44 & 0.00 & 13.52 \\
\hline & Unused land & 0.00 & 0.00 & 0.00 & 0.00 & 0.00 & 0.00 & 0.00 \\
\hline & Total & 972.96 & 917.44 & 1282.98 & 45.02 & 23.56 & 0.39 & 3242.35 \\
\hline
\end{tabular}

forms of land use changes in the Upper Fenhe watershed; the area of forest and grassland increased and the area of farmland decreased. Farmland showed the largest change. It was transformed into grassland in the northern part of the watershed due to the implementation of the "grain for green" government conservation program that compensated farmers for converting arable land to grassland. Meanwhile, due to the social development, the area of built-up land increased markedly at the expense of farmland. Finally, a tiny proportion of it was changed into water or wetland and unused land. In the southeast, a part of the watershed grassland was turned into farmland. Overall, the vegetation cover increased from 1995 to 2010, during periods of increased soil and water conservation measures.

4.2. Model Calibration and Validation. Parameter sensitivity analysis was carried out using the model parameters identified from the instructions for the calibration of the SWAT model, as given in the user's manual [29]. The model was calibrated with a comprehensive model calibration method [30]. The results of sensitivity analysis for the Upper Fenhe River watershed and the value of the parameters are shown in Table 4.

Comparisons between simulated and observed monthly streamflow values in the periods of calibration and validation are shown in Figure 4. Good matches were shown between simulated and observed values, except in 1997 and 2000. In these two years, the simulated runoff was overestimated for both Jingle and Hecha. For 1997, this may be because the water stored in the watershed in two consecutive wet years (1995 and 1996) was released in the subsequent year. For 2000, the overestimation may have happened because 1999 was an extremely dry year, and water bodies such as small swamps and lakes were dry, and the soil was also very dry. This was followed by heavy rain in 2000 that firstly wetted the soil, filled the dry water bodies, and did not form surface 
TABLE 4: The results of parameter sensitivity analysis and calibration.

\begin{tabular}{|c|c|c|c|c|}
\hline Parameter & Definition & Hydrologic process or variable affected & Rank & Value \\
\hline Alpha_Bf & Baseflow recession constant & Baseflow & 1 & 0.084 \\
\hline $\mathrm{Cn} 2$ & Moisture condition curve number & Surface runoff & 2 & $30 \sim 92$ \\
\hline Ch_K2 & Effective hydraulic conductivity in main channel alluvium $(\mathrm{mm} / \mathrm{h})$ & Concentration of channel & 3 & 10 \\
\hline Esco & Soil evaporation compensation factor & Soil water and soil evaporation & 4 & 0.6 \\
\hline Sol_K & Saturated hydraulic conductivity of first layer $(\mathrm{mm} / \mathrm{h})$ & Infiltration and soil water & 5 & $0 \sim 2000$ \\
\hline Sol_Z & Depth from soil surface to bottom of layer ( $\mathrm{mm})$ & Soil water & 6 & $0 \sim 3500$ \\
\hline Canmx & Maximum canopy storage (mm) & Interception & 7 & $0 \sim 10$ \\
\hline Sol_Awc & Available soil water capacity $(\mathrm{mm} / \mathrm{mm})$ & Soil water & 8 & $0.0125 \sim 0.5$ \\
\hline
\end{tabular}

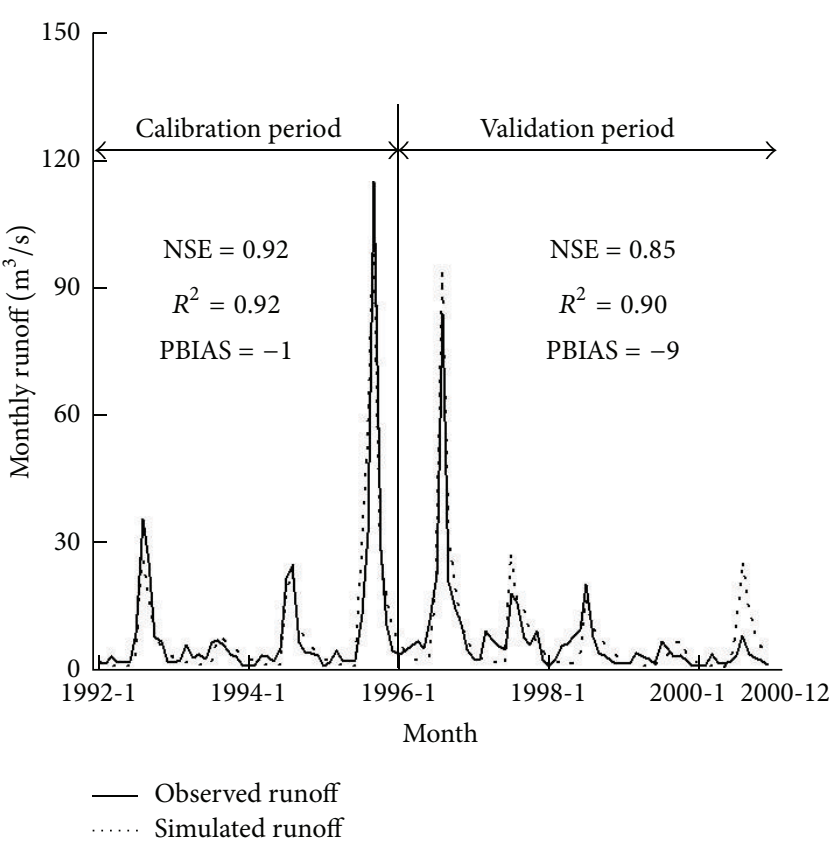

(a)

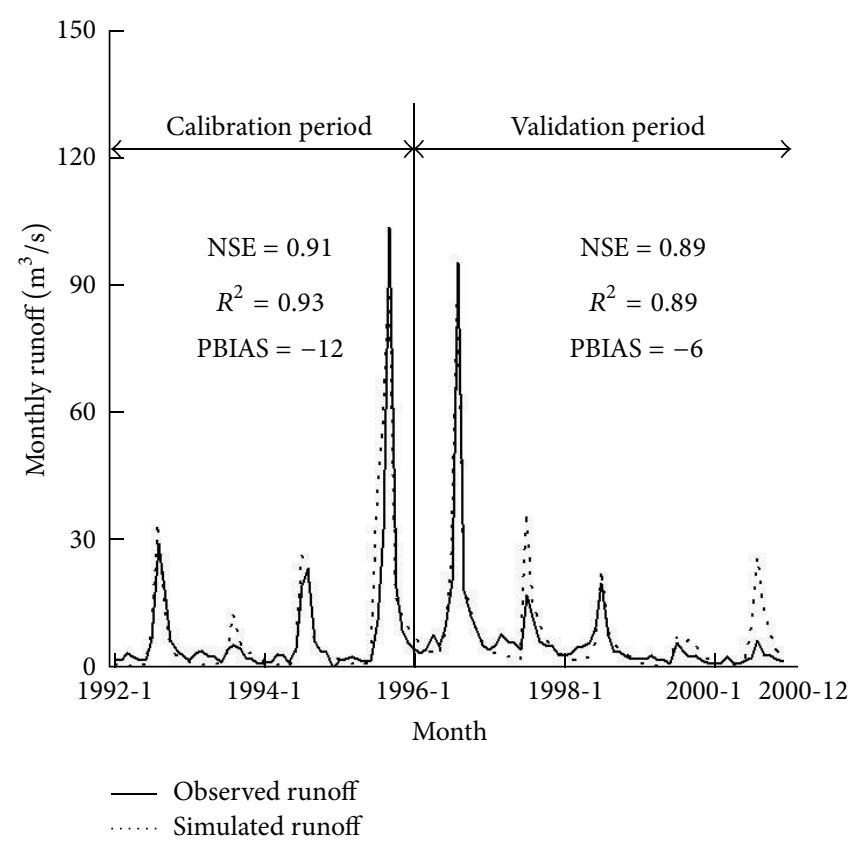

(b)

FIgURE 4: Monthly simulated and observed runoff in the Upper Fenhe River watershed. ((a) Hecha station; (b) Jingle station.)

runoff. This study did not take into account impounding of water in small water bodies which could have resulted in the overestimation of the actual runoff in 2000.

All NSE and $R^{2}$ values for the monthly calibration and validation were above 0.80 , and PBIAS values were in the range of $-15 \%$ to 0 (most PBIAS values were in the range of $-10 \%$ to 0 ), suggesting very good model performance [30]. The overall performance of the model was very good as shown in Figure 4.

\subsection{Contribution of Individual LULC Changes to Watershed} Water Yield. The proportional contributions of five LULC changes (i.e., farmland, forest, grassland, water or wetland, and built-up land) and simulated water yield (WY) are shown in Figure 5. Grassland, farmland, and forest were the main LULC changes in the Upper Fenhe River watershed, and the sum of their areas accounted for $98 \%$ of the total area. Their contributions to water yield were up to about $98 \%$ but there was no obvious positive correlation between the area of individual LULC changes and their proportional contributions to watershed WY. The grassland class includes mainly moderately dense and sparse grassland and very little dense grassland, so its water-yielding capacity was large. Although the area of forested land was much less than that of the grassland, its contribution to watershed WY was slightly more than the grassland's, because forests in this watershed are mainly shrubs and sparse trees. In addition, the rain mostly came in the form of high-intensity storms, which could reduce the amount of canopy interception compared with light rain. This is similar to the results obtained by Hao et al. (2004) in the upper Luohe River watershed and Song and $\mathrm{Ma}$ (2008) in the Nanhe River basin in the Longxi Loess Plateau $[6,7]$. The area of farmland was between that for forests and grasslands, but its water-yielding capacity was much less. The farmland in the Upper Fenhe River watershed is terraced and used to grow close and straight row-seeded wheat and maize which greatly reduce the water yield.

By comparing the percentages of the area of each land use type and their contribution to water yield, it was found that an increase of built-up land was the main cause of increases 


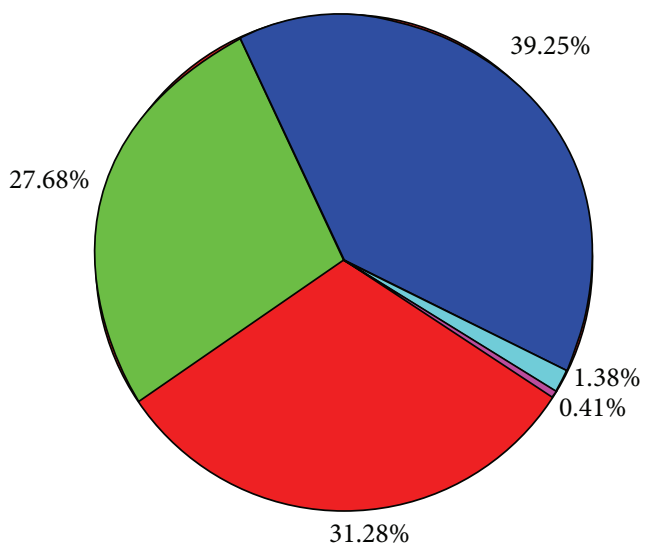

(a) Land use in 1995

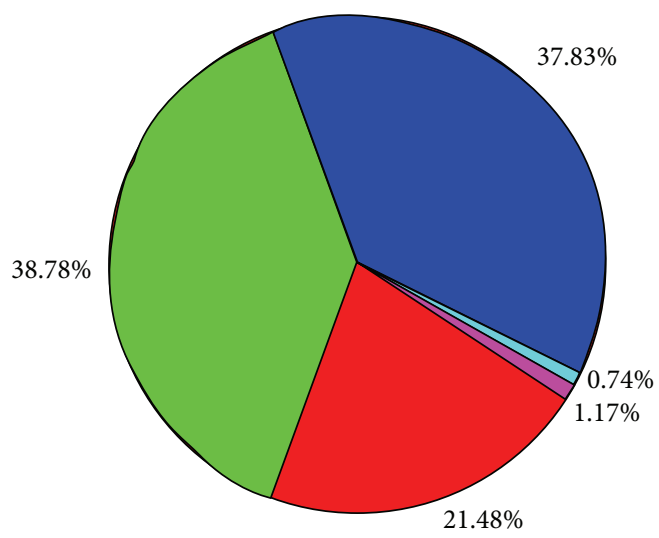

\begin{tabular}{l|l} 
Forest & Built-up land \\
Grassland & Farmland \\
Water or wetland &
\end{tabular}

(c) WY with 1995 land use

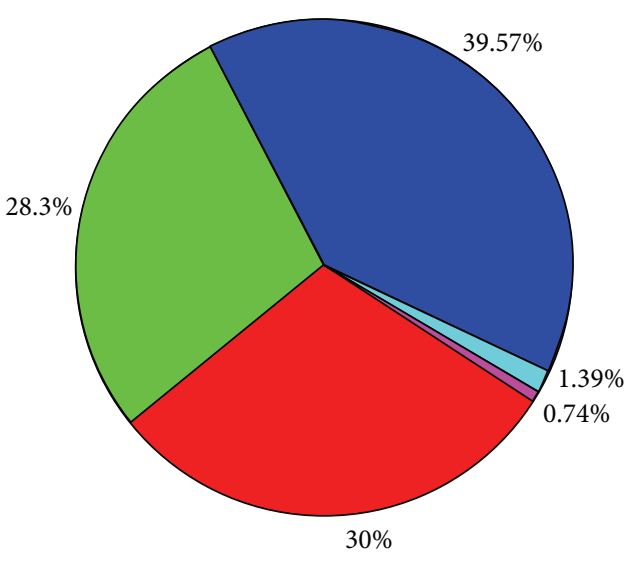

(b) Land use in 2010

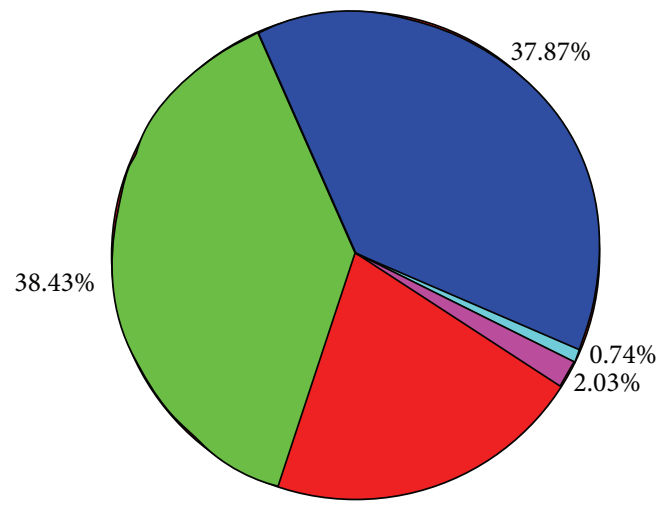

$20.93 \%$

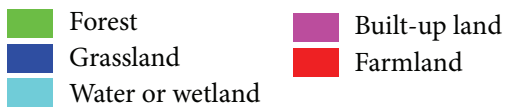

(d) WY with 2010 land use

FIgURE 5: Percentage of each LULC change and its contribution to the total average annual water yields (WY) for the Upper Fenhe River watershed from 1992 to 2000.

of runoff, although the area of built-up land was very small. This is because its water-yielding capacity was the highest due to little initial loss and infiltration and rapid rainfall-runoff processes $[9,31]$.

As LULCs changed from 1995 to 2010, the contribution of individual LULC change to watershed WY changed too, but the change process was complex, because the WY is an integrated result of LULCs, soil, topography, and climate.

\subsection{Impacts of LULC Changes on Hydrology at the Basin} Scale. The average basin values of P, PET, AET, WY, and SW simulated from each LULC map in 1995 and 2010 are shown in Table 5. Compared to the LULC change baseline year of 1995, the average annual WY over the watershed was $0.13 \mathrm{~mm}$ higher in 2010. Similar to WY, average annual PET with LULC in 1995 was $1026 \mathrm{~mm}$; it increased to $1028 \mathrm{~mm}$ by 2010. The AET increased from $391 \mathrm{~mm}$ for LULC in 1995 to $393 \mathrm{~mm}$ for LULC in 2010. On the contrary, the average annual SW for LULC in 2010 was $0.71 \mathrm{~mm}$ lower than that in 1995.
Furthermore, compared to the LULC baseline year 1995, the annual PET, AET, and SW for each year from 1992 to 2000 for LULC change in 2010 changed in a similar manner as the average annual PET, AET, and SW. But in contrast to the size of the average annual WY for LULC in 1995 and 2010, the annual WY for each year in this period did not increase consistently. For example, in years of abundant precipitation, such as 1995 and 1996, the annual WY for the LULC change in 1995 was higher than that in 2010. This indicated that the precipitation could affect the impacts of the LULC changes on the hydrology in this region, which was also found by Hao et al. (2004) in the upper Luohe River watershed [6].

The comparison of variations of PET and AET and changes in LULCs suggested that the increase of annual PET could be mainly attributed to returning cropland to forest and grassland and to urban expansion from 1995 to 2010. Further comparison between changes in WY and changes of LULCs indicated that an increase of WY was mainly due to increases of urbanization, which can increase the area of impervious surfaces, increase runoff, and decrease 
TABLE 5: Annual basin values of hydrologic features for the Upper Fenhe River watershed on the different land use from 1992 to 2000 (mm).

\begin{tabular}{lccccccccc}
\hline \multirow{2}{*}{ Year } & \multirow{2}{*}{$\mathrm{P}$} & \multicolumn{3}{c}{ Scenario with land use in 1995 } & \multicolumn{3}{c}{ Scenario with land use in 2010 } \\
& & PET & ET & WY & SW & PET & ET & WY & SW \\
\hline 1992 & 540.96 & 987.47 & 423.23 & 66.42 & 41.10 & 989.30 & 426.06 & 66.40 & 40.37 \\
1993 & 395.4 & 1017.43 & 359.38 & 34.74 & 36.10 & 1019.25 & 361.25 & 34.90 & 35.66 \\
1994 & 493.39 & 1029.46 & 409.19 & 67.96 & 38.68 & 1031.40 & 412.00 & 68.04 & 37.63 \\
1995 & 709.2 & 1000.44 & 418.90 & 215.99 & 54.46 & 1002.42 & 421.12 & 215.94 & 53.76 \\
1996 & 618.65 & 966.47 & 427.45 & 166.85 & 53.57 & 968.45 & 430.58 & 166.51 & 52.48 \\
1997 & 437.26 & 1048.62 & 359.69 & 76.13 & 49.58 & 1050.60 & 361.02 & 76.82 & 49.03 \\
1998 & 448.72 & 1081.87 & 403.59 & 50.94 & 43.10 & 1083.77 & 405.50 & 51.27 & 42.78 \\
1999 & 327.71 & 1086.06 & 294.28 & 33.34 & 45.65 & 1088.06 & 297.30 & 33.41 & 45.17 \\
2000 & 501.18 & 1020.10 & 424.42 & 58.84 & 54.54 & 1021.87 & 426.83 & 59.09 & 53.52 \\
\hline Mean & 496.94 & 1026.44 & 391.12 & 85.69 & 46.31 & 1028.35 & 393.52 & 85.82 & 45.60 \\
\hline
\end{tabular}

Note: P: precipitation; PET: potential evapotranspiration; ET: actual evapotranspiration; WY: water yield; SW: soil water.

TABLE 6: LULC changes and average annual hydrologic features from 1992 to 2000 of three subbasins.

\begin{tabular}{|c|c|c|c|c|c|c|}
\hline \multirow{2}{*}{$\begin{array}{l}\text { Subbasin } \\
\text { LULC scenario }\end{array}$} & \multicolumn{2}{|c|}{ Number 7} & \multicolumn{2}{|c|}{ Number 17} & \multicolumn{2}{|c|}{ Number 35} \\
\hline & 1995 & 2010 & 1995 & 2010 & 1995 & 2010 \\
\hline Total area $\left(\mathrm{km}^{2}\right)$ & 109.9 & 109.9 & 97.5 & 97.5 & 340 & 340 \\
\hline Farmland (\%) & 53.54 & 26.16 & 19.56 & 19.59 & 29.87 & 32.45 \\
\hline Forest (\%) & 9.31 & 17.42 & 49.6 & 46.51 & 15.57 & 16.78 \\
\hline Grassland (\%) & 36.98 & 55.35 & 28.1 & 31.18 & 52.75 & 48.23 \\
\hline Water or wetland (\%) & 0.01 & 0.72 & 2.29 & 2.29 & 1.25 & 1.24 \\
\hline Built-up land (\%) & 0.16 & 0.35 & 0.45 & 0.43 & 0.56 & 1.3 \\
\hline $\mathrm{P}(\mathrm{mm})$ & 492.01 & 492.01 & 599.03 & 599.03 & 473.68 & 473.68 \\
\hline $\operatorname{PET}(\mathrm{mm})$ & 918.93 & 926.55 & 1077.47 & 1077.5 & 1072.05 & 1072.18 \\
\hline $\mathrm{ET}(\mathrm{mm})$ & 396.89 & 403.63 & 457.99 & 469.51 & 380.7 & 380.08 \\
\hline $\mathrm{WY}(\mathrm{mm})$ & 64.74 & 66.57 & 124.43 & 116.62 & 71.17 & 72.17 \\
\hline $\mathrm{SW}(\mathrm{mm})$ & 74.84 & 72.22 & 71.47 & 58.01 & 24.93 & 23.12 \\
\hline
\end{tabular}

infiltration [9, 31]. An association between the decreases of SW and forest, grassland, and built-up land expansion from 1995 to 2010 could be indicated from the comparison between variations of average annual SW and changes in LULC from 1995 to 2010. Expansion of forest, grassland, and built-up land by replacing them with farmland could promote water infiltration and drainage because of well-developed root systems and prevention of infiltration due to increases in the areas of impervious surfaces.

4.5. Impacts of LULC Changes on Hydrology at the Subbasin Scale. Three subbasins (numbers 7, 17, and 35 in Figure 1) with obvious LULC changes were selected for analysis of the impacts of LULC changes on hydrology at the subbasin scale, and the results are shown in Table 6 . In subbasin number 7 , the area of farmland decreased sharply, and the areas of forest, grassland, water, and built-up land increased from 1995 to 2010. The PET, AET, and WY increased, and, in contrast, the SW decreased. In subbasin number 17 only the forested area decreased and grassland area increased a little, so the impacts on hydrology were that AET increased clearly and WY and SW decreased. In subbasin number 35, areas of farmland, forest, and built-up land increased and grassland decreased, and WY increased and SW decreased. By comparing the
LULC changes and the hydrological responses to them in these three sun-basins, obvious LULC changes may not show obvious impacts on hydrology, which means different combinations of LULCs may produce similar hydrological effects. Furthermore, the impacts of the same LULC changes on hydrology may be different under the conditions of different precipitation intensity and distribution.

\section{Conclusions}

In this study we aimed to investigate the impacts of LULC changes on hydrology in China's Loess Plateau. Major research findings and their implication on practices and future research are as follows.

From 1995 to 2010, the main land use changes were the transformations of farmland to forests and from farmland to grassland, and the area of built-up land increased at the expense of farmland. These changes were due to the implementation of watershed management measures and social and economic development. For the contribution of each LULC to the total WY of the watershed, the forest, grassland, and farmland areas were the largest contributors, with up to about $39 \%, 38 \%$, and $21 \%$, respectively. The land use that produced the greatest water yield was shown to be 
built-up land, which was higher than any other land use, followed by forest, grassland, and farmland.

Accompanying the LULC changes in the Upper Fenhe River watershed, increases in PET, AET, and WY indicated soil and water conservation practices increased runoff, while the expansion of the forest and grassland increased the PET and AET. In addition, the consumption of SW was increased by vegetation combined with decreased infiltration because increases of the built-up land resulted in decreases in SW. Furthermore, the precipitation could affect the impacts of LULC changes on the hydrologic components in this arid and semiarid area.

The approach used in this study simply determined contributions of individual LULC classes to the total discharge, providing quantitative information for decision-makers to make better choices for land and water resource planning and management. This approach also provides a solid example of the potential of hydrologic modeling using remotely sensed digital LULCs in understanding the impacts of landscape change on water provisioning, a vital ecosystem service in the Loess Plateau of China. It can be widely applied to a variety of watersheds, where time-sequenced digital land cover data are available, and to predict hydrological consequences to LULC changes.

\section{Conflict of Interests}

The authors declare no conflict of interests.

\section{Acknowledgments}

This work was supported by the International Science \& Technology Cooperation Program of China (2012DFA20770 and 2013DFG70990), the National Natural Science Foundation of China (41201043 and 91125007), the National Key Technology R\&D Program (2011BAC07B05), and Shanxi Province Science Foundation for Youths (2012021026-3).

\section{References}

[1] J. A. Foley, R. DeFries, G. P. Asner et al., "Global consequences of land use," Science, vol. 309, no. 5734, pp. 570-574, 2005.

[2] E. F. Lambin, B. L. Turner, H. J. Geist et al., "The causes of landuse and land-cover change: moving beyond the myths," Global Environmental Change, vol. 11, no. 4, pp. 261-269, 2001.

[3] N. Ramankutty and J. A. Foley, "Estimating historical changes in global land cover: croplands from 1700 to 1992," Global Biogeochemical Cycles, vol. 13, no. 4, pp. 997-1027, 1999.

[4] L. M. Mango, A. M. Melesse, M. E. McClain, D. Gann, and S. G. Setegn, "Land use and climate change impacts on the hydrology of the upper Mara River Basin, Kenya: results of a modeling study to support better resource management," Hydrology and Earth System Sciences, vol. 15, no. 7, pp. 2245-2258, 2011.

[5] D. N. Khoi and T. Suetsugi, "The responses of hydrological processes and sediment yield to land-use and climate change in the Be River Catchment, Vietnam," Hydrological Processes, vol. 28, no. 3, pp. 640-652, 2014.

[6] F. Hao, L. Chen, C. Liu, and D. Dai, "Impact of land use change on runoff and sediment yield," Journal of Soil and Water Conservation, vol. 18, no. 3, pp. 5-8, 2004.
[7] Y.-H. Song and J.-H. Ma, "SWAT-Aided research on hydrological responses to ecological restoration; a case study of the Nanhe River Basin in Huajialing of Longxi Loess Plateau," Acta Ecologica Sinica, vol. 28, no. 2, pp. 636-644, 2008.

[8] G. Ghaffari, S. Keesstra, J. Ghodousi, and H. Ahmadi, "SWATsimulated hydrological impact of land-use change in the Zanjanrood basin, Northwest Iran," Hydrological Processes, vol. 24, no. 7, pp. 892-903, 2010.

[9] W. Nie, Y. Yuan, W. Kepner, M. S. Nash, M. Jackson, and C. Erickson, "Assessing impacts of Landuse and Landcover changes on hydrology for the upper San Pedro watershed," Journal of Hydrology, vol. 407, no. 1-4, pp. 105-114, 2011.

[10] Y. Wang, W. Ji, X. Yu et al., "The impact of urbanization on the annual average temperature of the past 60 years in Beijing," Advances in Meteorology, vol. 2014, Article ID 374987, 9 pages, 2014.

[11] Y. Li, J. Fan, Z. Hu, Q. Shao, L. Zhang, and H. Yu, "Influence of land use patterns on evapotranspiration and its components in a temperate grassland ecosystem," Advances in Meteorology. In press.

[12] X. Yao, Z. Wang, and H. Wang, "Impact of urbanization and land-use change on surface climate in middle and lower reaches of the Yangtze River, 1988-2008," Advances in Meteorology. In press.

[13] M. López-Vicente, J. Poesen, A. Navas, and L. Gaspar, "Predicting runoff and sediment connectivity and soil erosion by water for different land use scenarios in the Spanish Pre-Pyrenees," Catena, vol. 102, pp. 62-73, 2013.

[14] N. Ohana-Levi, A. Karnieli, R. Egozi, A. Givati, and A. Peeters, "Modeling the effects of land-cover change on rainfall-runoff relationships in a semi-arid, Eastern Mediterranean watershed," Advances in Meteorology. In press.

[15] G. Wang, H. Yang, L. Wang, Z. Xu, and B. Xue, "Using the SWAT model to assess impacts of land use changes on runoff generation in headwaters," Hydrological Processes, vol. 28, no. 3, pp. 1032-1042, 2014.

[16] X. Li, "A review of the international researches on land use/land cover change," Acta Geographica Sinica, vol. 51, no. 6, pp. 553$558,1996$.

[17] Q. F. Zhang, F. Q. Wu, L. Wang, L. Yuan, and L.-S. Zhao, "Application of PCA integrated with CA and GIS in ecoeconomic regionalization of Chinese Loess Plateau," Ecological Economics, vol. 70, no. 6, pp. 1051-1056, 2011.

[18] C. Shi, Y. Zhou, X. Fan, and W. Shao, "A study on the annual runoff change and its relationship with water and soil conservation practices and climate change in the middle Yellow River basin," Catena, vol. 100, pp. 31-41, 2013.

[19] J. Zhang, "Comprehensive treatment for large basin and harmonious development of upstream and downstream-survey on comprehensive harness engineering of soil and water conservation for upper Fenhe River," Shanxi Water Resources, vol. 21, no. 4, pp. 5-9, 2005.

[20] X. Wang and X. Nie, "Analysis on the benefit of soil and water conservation in the upper-reach of Fenhe reservoir-a case study of comprehensive management to Fenhe during the second phase in Jingle county," Journal of Shanxi Agricultural University (Social Science Edition), vol. 6, no. 3, pp. 237-240, 2007.

[21] B. Yang, "Viewing the function of integrated treatment of soil and water conservation conducted in the upper Fenhe River from sediment discharge variations at Jingle hydrometric station," Soil and Water Conservation in China, no. 10, pp. 32-34, 2007. 
[22] W. Meng, S. Wang, and J. Niu, "Upstream Fenhe River the Basin humanity moves under the forest cover change," Journal of Taiyuan Normal University (Natural Science Edition), vol. 6, no. 1, pp. 75-79, 2007.

[23] Z. Li, W.-Z. Liu, X.-C. Zhang, and F.-L. Zheng, "Impacts of land use change and climate variability on hydrology in an agricultural catchment on the Loess Plateau of China," Journal of Hydrology, vol. 377, no. 1-2, pp. 35-42, 2009.

[24] H. Li, Y. Zhang, J. Vaze, and B. Wang, "Separating effects of vegetation change and climate variability using hydrological modelling and sensitivity-based approaches," Journal of Hydrology, vol. 420-421, pp. 403-418, 2012.

[25] J. G. Arnold, R. Srinivasan, R. S. Muttiah, and J. R. Williams, "Large area hydrologic modeling and assessment part I: model development," Journal of the American Water Resources Association, vol. 34, no. 1, pp. 73-89, 1998.

[26] J. Sun, Y. Liu, Y. Wang, G. Bao, and B. Sun, "Tree-ring based runoff reconstruction of the upper Fenhe River basin, North China, since 1799 AD," Quaternary International, vol. 283, pp. 117-124, 2013.

[27] X. Wang, "Studies on ecology and environment improvement of Fenhe reservoir and its upstream water sources," China Water Resources, vol. 16, pp. 44-47, 2008.

[28] S. Neitsch, J. Arnold, J. Kiniry, J. Williams, and K. King, Soil and Water Assessment Tool: Theoretical Documentation, Version 2005, Texas A\&M University, College Station, Tex, USA, 2005.

[29] Z. Lu, S. Zou, Z. Yin, A. Long, and B. Xu, "A new suitable method for SWAT model calibration and its application in data-scarce basins," Journal of Lanzhou University (Natural Sciences), vol. 48, no. 1, pp. 1-7, 2012.

[30] D. N. Moriasi, J. G. Arnold, M. W. Van Liew, R. L. Bingner, R. D. Harmel, and T. L. Veith, "Model evaluation guidelines for systematic quantification of accuracy in watershed simulations," Transactions of the ASABE, vol. 50, no. 3, pp. 885-900, 2007.

[31] J. Franczyk and H. Chang, "The effects of climate change and urbanization on the runoff of the Rock Creek basin in the Portland metropolitan area, Oregon, USA," Hydrological Processes, vol. 23, no. 6, pp. 805-815, 2009. 

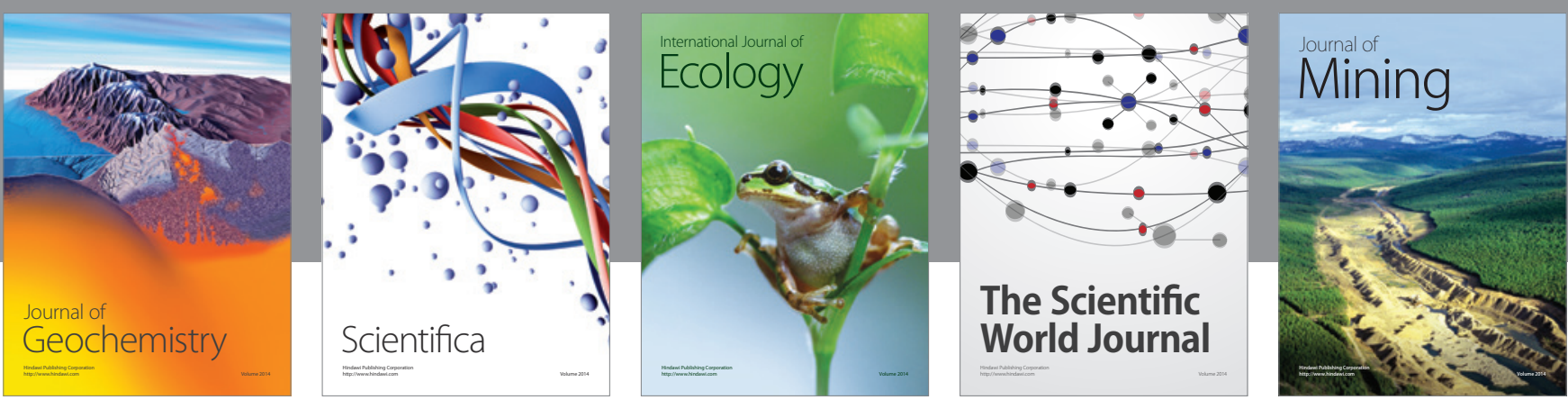

The Scientific World Journal
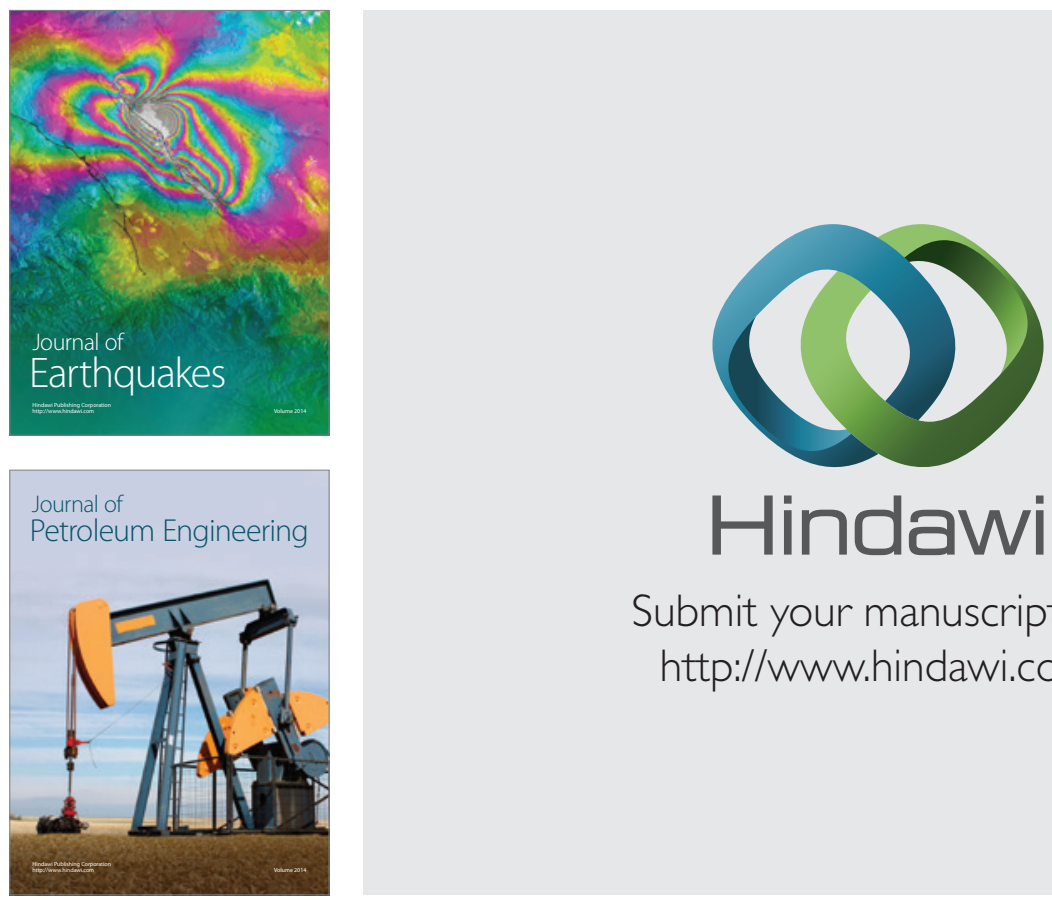

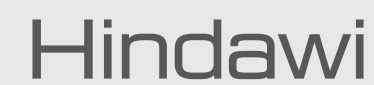

Submit your manuscripts at

http://www.hindawi.com
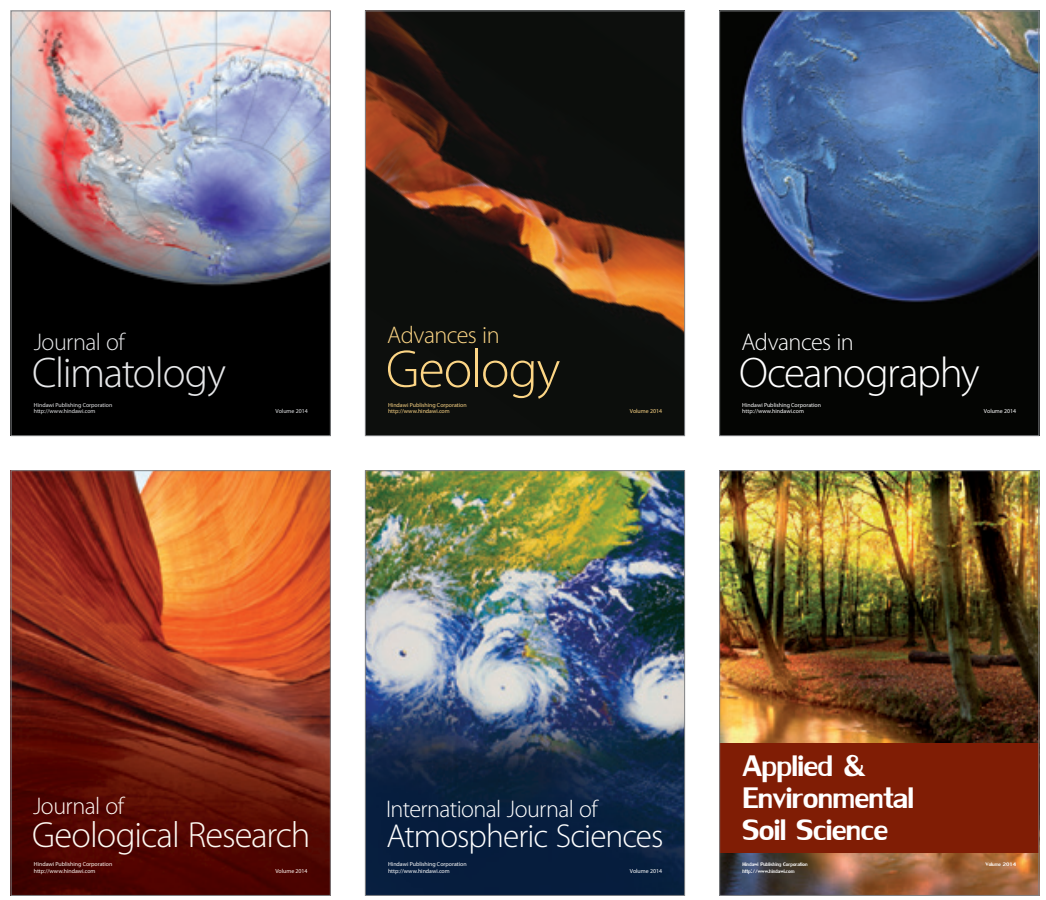
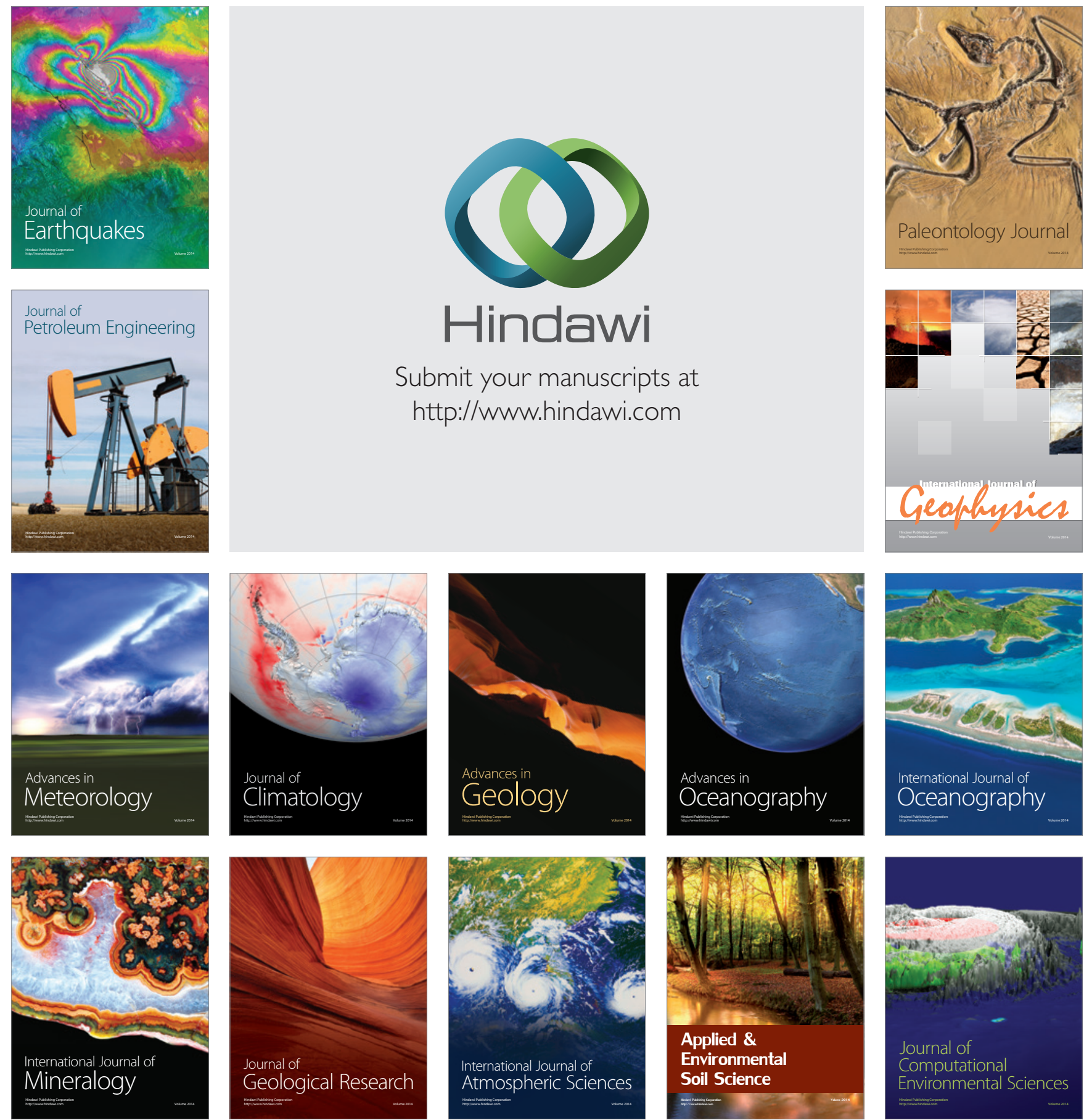